\title{
A Novel approach for Stacked Patch antenna for large bandwidth applications
}

\author{
Rushit D Trivedi $^{\# 1}$, Dr. Vedvyas Dwivedi ${ }^{\# 2}$, \\ ${ }^{\# 1}$ Research Scholar, JJTU University, Dist. Jhunjhunu, Rajasthan - 333 001, India, \\ ${ }^{\# 2}$ Director C.U.Shah Engineering College, Surendranagar, Gujarat India
}

\begin{abstract}
A Stacked rectangular $U$ shaped slot microstrip patch antenna has been investigated and its performance has been analyzed with the aid of Ansoft HFSS. An additional E shaped conductive plate of comparable dimensions was placed above the patch in order to enhance the bandwidth. A bandwidth of 1.02 GHz for VSWR $<2$ has been achieved for stacked $E$ shape patch designed to operate in the $S$-band. The radiation patterns of the proposed antenna are found to be relatively constant throughout the entire band of operation. The antenna proposed can be used for wireless LAN and compact transceivers.
\end{abstract}

Keywords: Stacked Microstrip Patch Antenna, Ansoft HFSS, Band width

\section{INTRODUCTION}

A microstrip patch antenna is very attractive owing to its low cost, conformability and ease of manufacture [2]. However, the primary barrier to implement this type of antenna in many applications is its limited bandwidth. However, in many applications, such as mobile or satellite communications, much larger bandwidth or dual

frequency behaviour is required. Several techniques, such as using thicker substrates [2], reactive loading [3], coupled resonators [4], or resonant aperture [5], have been suggested in the last few years to resolve this problem.

A standard configuration for a microstrip antenna is the single rectangular patch. It consists of a sandwich of two parallel conducting layers separated by a single thin dielectric substrate. The lower conductor functions as a ground plane and the upper conductor represent the antenna radiating part. This is a simple configuration that is rugged and relatively easy to fabricate, but it is

limited in bandwidth. The bandwidth limit is $0.5 \%-2 \%$. Nowadays several methods have been

attempted to increase the bandwidth. One effective method to overcome this problem is to add a second patch in front of the basic one resulting in the so called dual patch microstrip antenna shown in Fig 1. The concept of stacking patches is realized through electromagnetic coupling form which gives bandwidth enhancement [1]. It has been shown that the obtainable bandwidth of a microstrip antenna is approximately proportional to its volume [6]. However, it is possible to increase the bandwidth of

microstrip antenna by simply using thicker substrates . This technique introduces several problems. A thicker substrate will support surface waves, which will deteriorate the radiation pattern as well as reduce the radiation efficiency. Also problem with the feeding technique of the antenna arise. In addition, depending upon the z-direction, higher order modes may arise, introducing further distortions in the pattern and impedance characteristics. In view of the above problems, electromagnetic coupling (instead of direct coupling) has been studied as a possible feed technique for electrically thick microstrip antennas

The basic geometry of the stacked dual-patch electromagnetic coupled microstrip antenna is shown in

Fig. 2. The top and bottom patches are

referred as the radiating patch and the feeding patch, respectively. Ansoft HFSS has been used to analyze various types of microstrip antennas. Here, it is used to analyse stacked rectangular microstrip patch antenna. The impedance locus and the radiation pattern are the dominant characteristics analysed by the software. In bottom patch $\mathrm{U}$ slot is etched which gives resonance around $3.6 \mathrm{Ghz}$ to $4 \mathrm{GHz}$. Further improvement is done with the help of E shaped stacked patch.

\section{ANTENNA CONFIGURATION}

The geometry of the proposed stacked dual-patch electromagnetic coupled microstrip antenna of the presented work is shown in Fig. 2. A rectangular patch (lower patch) of dimensions $60 \times 70 \mathrm{~mm}$ operating at resonance frequency from $3.3 \mathrm{GHz}$ to $4.36 \mathrm{GHz}$ is printed on the ground plane with dielectric material of thickness $6 \mathrm{~mm}$ and dielectric constant $\varepsilon \mathrm{r}=1.07 . \mathrm{U}$ slot is etched from patch so as to get wider bandwidth. Its dimensions are indicating in Fig. 3 a. Another thin E shaped parasitic conducting patch (dimensions are indicating in Fig 3.b)is placed above the lower patch and is separated by foam ( $(\varepsilon=1.07)$ of height $10 \mathrm{~mm}$. The top element is excited via an electromagnetic coupling from the lower element, which is located closer to the 
ground plane and is connected directly to a coaxial feed line. The length of feeding patches operating at resonance frequency band from $3.3 \mathrm{GHz}$ to $4.36 \mathrm{GHz}$ for $\mathrm{TM}_{01}$ mode. The width of the feeding patch is determined from the ratio $\mathrm{W} / \mathrm{L}=1.5$.

Design parameters are:

Relative permittivity lower dielectric: 1.07

Relative permittivity upper dielectric: 1.07

Material used

Upper Substrate: Foam

Lower Substrate: Foam

Height of Upper and lower substrate:

$\mathrm{h}_{1}=6 \mathrm{~mm}$ and $\mathrm{h}_{2}=10 \mathrm{~mm}$

Coaxial feed position $(\mathrm{x}, \mathrm{y}):(0 \mathrm{~mm},-2 \mathrm{~mm})$

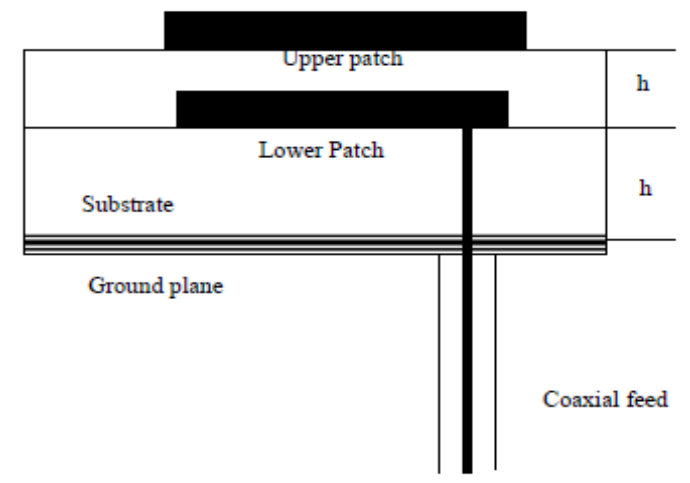

Fig. 1.a Stacked Microstrip Patch Antenna feed by co-axial probe

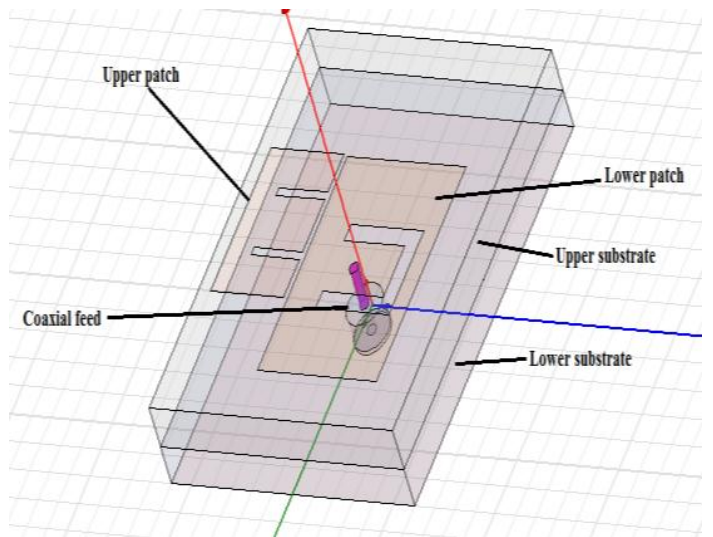

Fig. 1.b Proposed Model (Simulated in ANSOFT HFSS)

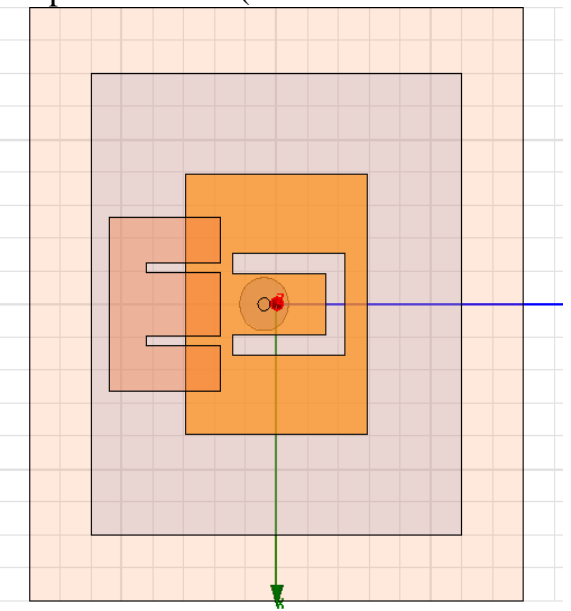

Fig. 2 Top view of Proposed Model 


\section{ANALYSIS MODEL OF THE PROBLEM}

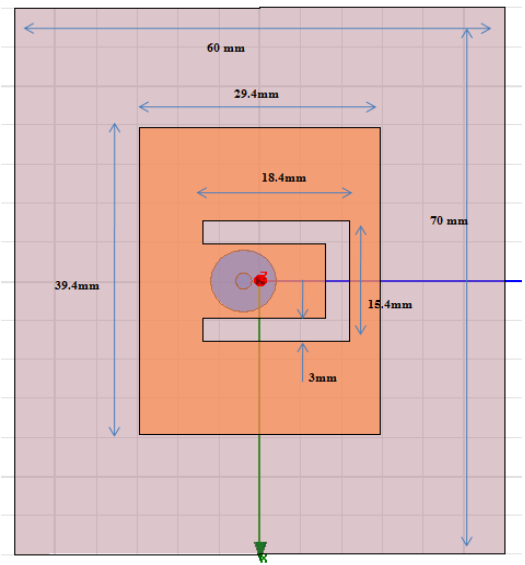

Fig. 3 a. Lower Patch Dimensions

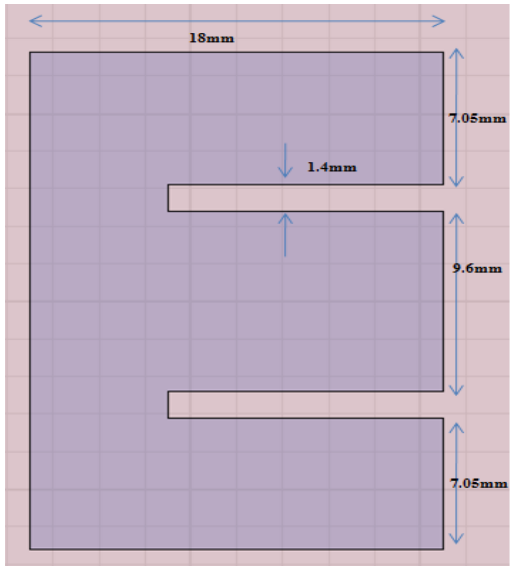

Fig. 3 b. Upper patch dimensions

The analysis of the problem geometry is carried out using the finite element method (FEM) by way of Ansoft HFSS, a proven commercial electromagnetic analysis tool [3]. The upper patch, lower patch and ground plane are defined as perfect conductor. The structure is enclosed in a radiation box allowing the expected maximum radiation in the forward direction as well as surface wave effects from the top patch and allowing the fold-over currents to radiate from the rear of the antenna which will be very minor amount of energy.

\section{SIMULATION RESULTS}

Convergence for $\Delta s=0.002$ was achieved in a total of 8 adaptive passes. The total number of tetrahedral required for this was 12864 - the analysis required about 6 minutes of execution with 437 MB RAM usage.

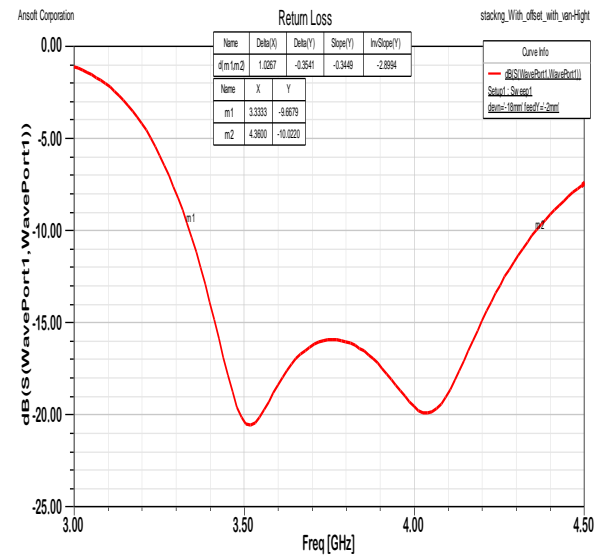

Fig. 4 Return loss graph (it shows resonant freq. is $5.3 \mathrm{GHz}$ ) 
The predicted input characteristics show a clear resonance from $3.3 \mathrm{GHz}$ to $4.36 \mathrm{GHz}$, the intended design frequency (see Fig.4). The VSWR plot also shows the same characteristics for desired radiation frequency.(Fig 5.). The bandwidth is improved up to $26 \%$ from this model.

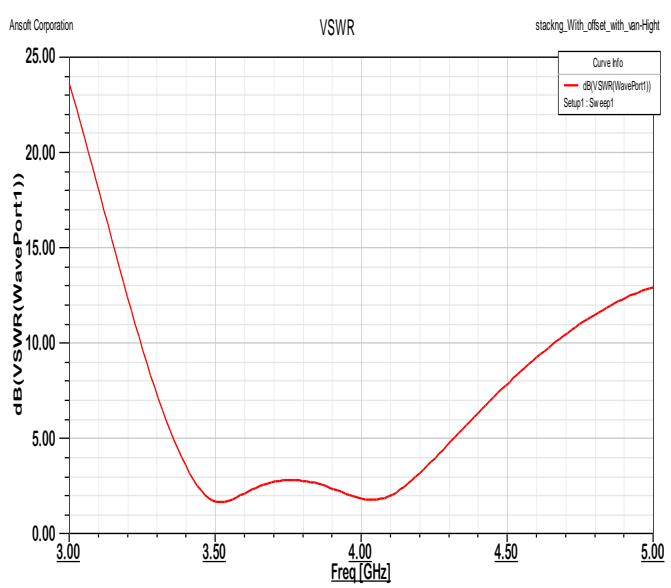

Fig. 5 VSWR (Voltage Standing Wave Ratio) graph (it shows resonant freq. is $5.3 \mathrm{GHz}$ )

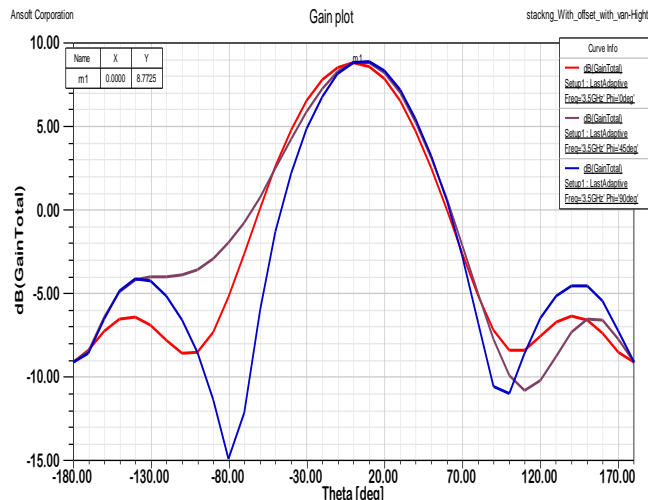

Fig. 6 Gain plot (8.6 dB gain)

Gain plot pattern shows the uniform radiation pattern in three planes and having good co polarization in bore sight around $8.7 \mathrm{dBi}$ gain is achieved with help of stacked patch antenna (Fig.6.).

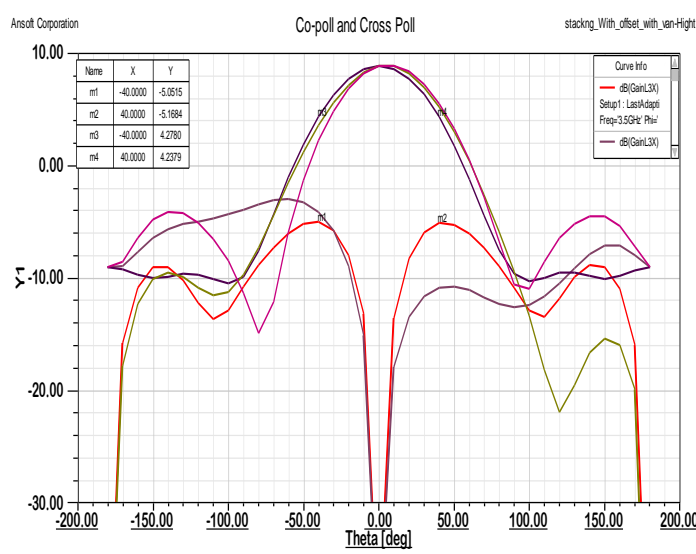

Fig. 7 Co poll and Cross poll result

The predicted radiation patterns for the proposed antenna geometry show an encouraging result. A gain of $8.7 \mathrm{dBi}$ is achieved which is expected from a stacked patch antenna supporting the fundamental mode of resonance. A front-to-back ratio of nearly $20 \mathrm{~dB}$ is achieved as the ground plane screens the patch radiation from the rear-hemisphere. Good cross-polar levels $(\sim-15 \mathrm{~dB})$ are predicted in both planes .The 3 dimensions radiation pattern shows very less back lobe is achieved. The electric field distribution is indicating in Fig 9 \& 10 which shows radiations are takes place from edges of the patch. 


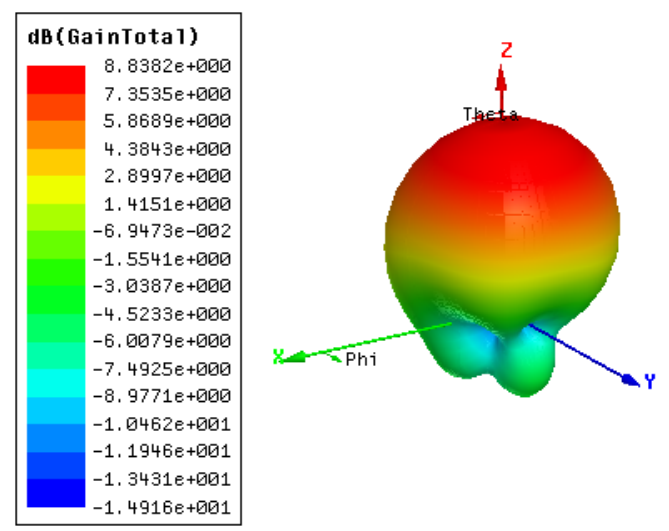

Fig. 8. Three dimension Gain Plot

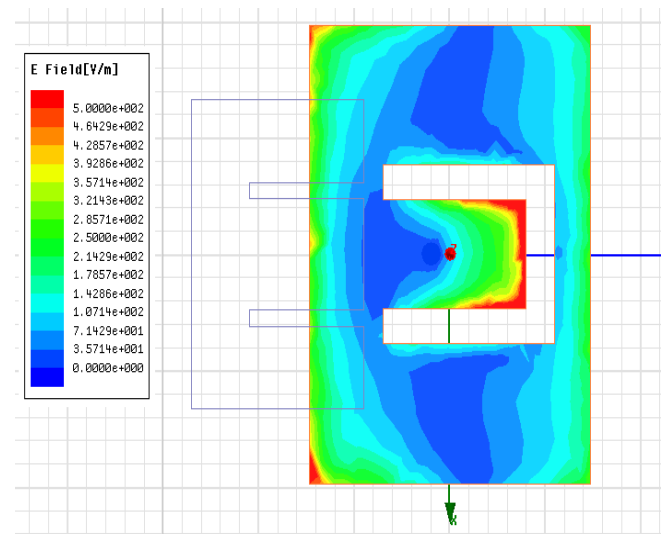

Fig. 9 Electric filed distribution in Lower Patch

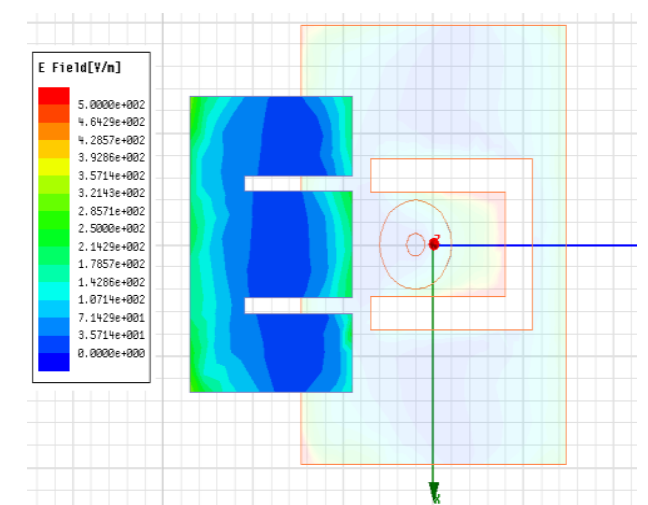

Fig.10 Electric filed distribution in Upper Patch

\section{CONCLUSION}

The results of coaxial fed stacked microstrip patch antenna is presented it analysis results are encouraging. The chosen patch geometry of $U$ shaped slot shape, excited with a coaxial fed is predicted to provide good impedance and radiation characteristics is improved by E shaped patch antenna. For the geometry presented, good directivity, back lobe and cross-polar performance is predicted. The $26 \%$ Impedance bandwidth is achieved in this paper and results are presented. The simulation of presented model is carried out using Ansoft HFSS software. Bandwidth is improved with this method and efficient gain and directivity is achieved 


\section{REFERENCES}

[1] Rushit D Trivedi,Dr. Vedvyas Dwivedi,:” Stacked Microstrip Patch Antenna: Gain and Bandwidth Improvement, Effect of Patch Rotation" IEEE Conf 2012,pp 45-48

[2] Kumar, G., and Ray, K.P.: 'Broadband microstrip antennas' (Artech House, Norwood, MA, 2003)

Chen, W., Lee, K.F., and Lee, R.Q.: 'Input impedance of coaxially fed rectangular microstrip antenna on electrically thick substrate', Microw. Opt. Technol. Lett., 1993, 6, (6), pp. 387-390

[3] Rushit D Trivedi,Khagindra K Soo,Rajeev Jyoti."cavity backed slot antenna”,IJ-CA-ETS journal,vol 2,pp 23-26,

[4] Nakano, H., and Vichien, K.: 'Dual-frequency square patch antenna with a rectangular notch', Electron. Lett., 1989, 25, (16), pp. 1067-1068

[5] Croq, F., and Pozar, D.M.: 'Multifrequency operation of microstrip antennas using aperture coupled parallel resonators', IEEE Trans.Antennas Propag., 1992, 40, (11), pp. 1367-1374

[6] Targonski, S.D., Waterhouse, R.B., and Pozar, D.M.: 'Design of wideband aperture-stacked patch microstrip antennas', IEEE Trans. Antennas Propag., 1998, 46, (9), pp. 1245-1251

[7] E. C., S. A. Long and W. F. Richards, "An experimental investigation of electrically thick rectangular microstrip antennas," IEEE Trans. Antennas Propagat., vol. AP-34, no. 6, pp 767-772, 1986.

[8] A.K Bhattacharjee., S.R Bhadra.,D.R. Pooddar and S.K. Chowdhury, "Equivalence of impedance and radiation properties of square and circular microstrip patch antennas," IEE Proc. vol.136, Pt, H, no.4, pp338-342.,1989.

[9] L. I.Basilio, M. A. Khayat, J. T.Williams, and S. A. Long, "The dependence of the input impedance on feed position of probe and microstrip line-fed patch antennas," IEEE Trans. Antennas Propagat., vol. 49, no. 1, pp 45-47, 2001.

[10] Z.N. Chen and M.Y.W.Chia, "Broadband suspended plate antenna with probe-fed strip," IEE Proc.- Microw. Ant. Prop., vol. 148, no.1,pp3 7-40,2001.

[11] I.J. Bahl and P. Bhartia, "Microstrip antennas," Artech Hous, Inc., 1980.

[12] A. Hussien, " Microstrip backfire antenna", M.Sc. Thesis, College of Science , Al-Nahrain university (Formerly Saddam University), Baghdad, Iraq, 1995.

[13] E. C., S. A. Long and W. F. Richards, "An experimental investigation of electrically thick rectangular microstrip antennas," IEEE Trans. Antennas Propagat., vol. AP-34, no. 6, pp 767-772, 1986.

[14] Z. N. Chen, M.Y.W.Chia, and C. L.Lim, "A stacked suspended plate antenna" Microwave and Optical Technology Letters, vol.37, no.5, pp 337-339, 2003.

[15] J. R. James and P. S. Hall, "Handbook of microstrip antennas," IEE Electromagnetic Waves Series 28, Peter Peregrinus Ltd, 1989.

[16] Y.T. Lo, P. Solomon, and W.F. Richards, "Theory and experiment on microstrip antennas," IEEE Trans. Antennas Propaga., vol. Ap-27, no. 2, pp.113 7-145,. 1979.

[17] W.F. Richards, Y.T. Lo, and D.D. Harrison, "An improved theory for microstrip antennas and applications," IEEE Trans. Antennas Propagat., vol. AP-29, no. 1, pp.38-46,1981.

[18] G. V. and A. V.D. Cappelle, "A study of the effect of the top patch in rectangular dual patch microstrip antenna," Ann. Telecom.., vol. 47, no. 3-4,pp.135-141, 1992.

[19] K.R. Carver and J.W. Mink, Microstrip antenna technology," IEEE Trans. Antennas Propagat., vol. Ap-29, pp.2-24, 1981.

[20] Shackelford, A.K., Lee, K.F., and Luk, K.M.: 'Design of small-size wide- bandwidth microstrip-patch antennas', IEEE Antennas Propag. Mag., 2003, 45, (1), pp. 75-83. 